\title{
Effect of Tannin-Rich Extract of Chasmanthera dependens on Piroxicam-induced Liver Damage in Male Wistar Rats
}

\author{
Tijani Stephanie Abiola ${ }^{1}$, Olori Ogaraya David ${ }^{1}$, Farombi Ebenezer Olatunde ${ }^{2}$ \\ ${ }^{1}$ Department of Biochemistry, Bowen University of Iwo, Nigeria \\ ${ }^{2}$ Drug Metabolism and Toxicology Research Laboratories, Department of Biochemistry, College of Medicine, University of Ibadan, \\ Nigeria
}

Background: Piroxicam is one of the nonsteroidal anti-inflammatory drugs used as antipyretic, analgesic and antiinflammatory drug often used for the relief of nonspecific fever condition and in arthritis. This study investigated the protective potential of tannin-rich extract of Chasmanthera dependens (TRECDS) against piroxicam-induced hepatotoxicity in male Wistar rats.

Materials and Methods: Thirty two rats were divided into four groups. Group 1 received normal saline and served as the control group, group 2 were given $20 \mathrm{mg} / \mathrm{kg}$ piroxicam only, while groups 3 and 4 were given $20 \mathrm{mg} / \mathrm{kg}$ piroxicam with the addition of 200 and $400 \mathrm{mg} / \mathrm{kg}$ of tannin-rich extract of Chasmanthera dependens, respectively. All rats were treated orally once daily for ten days.

Results: Administration of piroxicam caused liver atrophy demonstrated by significant rise in serum alanine aminotransferase (ALT), alkaline phosphatase (ALP), aspartate aminotransferase (AST), gamma-glutamyl transferase (GGT), glucose-6phosphate dehydrogenase (G6PDH) levels of albumin (ALB), bilirubin (BIL), total cholesterol (TCHOL), triglyceride (TRIGS) and low-density lipoprotein (LDL). Piroxicam also decreased high-density lipoprotein (HDL) level, enzymatic and nonenzymatic antioxidant levels significantly $(p>0.05)$ with attendant increase in oxidative stress indices in the liver of rats compared with control group. Histological assessment reveled severe damaged to the liver of rats. However, co-administration with TRECDS reversed these observations as evidenced in the histological results.

Conclusion: The findings of this study showed that exposure of rats to piroxicam provoked damage to the liver via oxidative damage and TRECDS has the potential of ameliorating the damage.

Keywords: hepatotoxicity, piroxicam, Chasmanthera dependens, oxidative stress

\section{Introduction}

Piroxicam is a non-steroidal anti-inflammatory drug (NSAID) that belongs to a group of enolic acids use in treatment of pain and inflammatory conditions as analgesic, antipyretic and anti-inflammatory drug. ${ }^{1}$ Its long time usage can cause various side effects ranging from gastrointestinal injury, kidney dysfunction, hepatotoxicity, and other processes associated with prostaglandins functions., ${ }^{2,3}$ Piroxicam mechanism of actions involves inhibition of

Date of submission: July 10, 2020

Last Revised: October 2, 2020

Accepted for publication: October 2, 2020

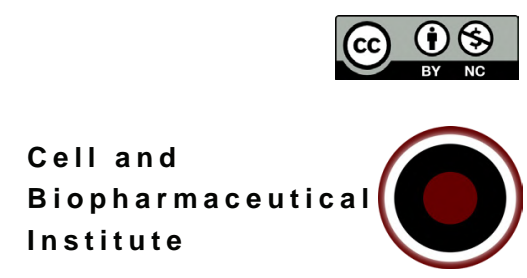


cyclooxygenase, an enzyme responsible for the synthesis of prostaglandin, generation of free radicals, several different forms of acute and chronic renal failure that can lead to sodium retention, hyperkalemia. ${ }^{4,5}$ The liver is a vital organ in xenobiotic metabolism thus predominantly susceptible to adverse effects produced by reactive metabolite from drug metabolism that can result in hepatotoxicity. ${ }^{6}$ The balance between the antioxidant defense and prooxidant conditions in humans has been suggested as a useful parameter in evaluating the risk of oxidative damage. ${ }^{?}$

Medicinal plants are reservoirs for numerous phytochemicals that work synergistically and some of these phytochemicals are well-known and have been used as remedial agents for a variety of ailments. ${ }^{89}$ Chasmanthera dependens is a plant usually found in home gardens. ${ }^{10}$ It is cultivated as a medicinal plant in west and central Africa. The plant is distributed from Sudan in the north to Ghana in the west coast, and spreads down south to Ethiopia and South Africa. Chasmanthera dependens has been reported containing different phytoconstituents including alkaloids most of which are quaternary protoberberine alkaloids and the non-phenolic quaternary alkaloids, oleic acid, tannin, steroids and phenol..$^{10}$ The plant is commonly used by traditional medical practitioners to cure sprained joints and bruises. ${ }^{11}$ The plant has also been reported to possess analgesic and anti-inflammatory properties on experimental animals. ${ }^{12,13}$ It is also use as a medication for venereal releases or as a common tonic for physical or nervous frailty in inflammatory and exhaustive illnesses but there are no scientifical evidence on its hepatoprotective activity. Thus, this study investigated the mechanism of action of tanninrich extract of Chasmanthera dependens stem (TRECDS) at subcellular levels in liver piroxicam-induced damage.

\section{Materials and methods}

\section{Plant Collection and Authentication}

Fresh stems of Chasmanthera dependens stem were obtained in a local garden at Oke Oba area in Iwo along Ibadan-Iwo express road, Osun state, Nigeria. Iwo is located on latitude $7.6292^{\circ} \mathrm{N}$ and longitude $4.1872^{\circ} \mathrm{E}$. The plant material was identified and authenticated at University of Ibadan with voucher number UIH -22478 by Esimekhuai, D.P.O.

\section{Preparation of the Plant Extract}

The stems were chopped into pieces and air dried at room temperature. The dried samples were pulverized with an electric blender, weighed and kept in an air-tight container prior to extraction.

The tannin-rich extract of Chasmanthera dependens was prepared by extracting $1 \mathrm{~kg}$ of powdered Chasmanthera dependens with 2.5 Litres of $70 \%$ acetone and heated at $50^{\circ} \mathrm{C}$ for 15 minutes with intermittent stirring, allowed to cool and filtered with cheese cloth. The filtrate obtained was subjected to further extraction using equal volume of diethyl ether in separating funnel and shaken vigorously, until complete separation. The tannin-rich layer which is in the lower layer was then collected and evaporated under reduced pressure using rotary (Edward Vacuum Cooperation, Crawley, England) at $40^{\circ} \mathrm{C}$. The aliquot obtained was freeze dried to obtain a dark brown extract of $20.17 \% \mathrm{w} / \mathrm{w}$ referred to as TRECDS. The dried extract was stored in an air tight container in the refrigerator at $-20^{\circ} \mathrm{C}$ and used for this study.

\section{Animals Preparation}

Thirty-two male Wistar rats (6 weeks, weighing 150-180 \pm 5 g) used in this study were obtained from the Department of Biochemistry University of Ibadan, Ibadan, Nigeria. The rats were housed in plastic cages and placed in a wellventilated rat house at the Department of Biochemistry, Bowen University, Iwo, Nigeria, to acclimatize for 14 days prior to the commencement of the experiment. The rats were fed with standard rat chows and water ad libitum throughout the experiment and subjected to natural photoperiod of $12-\mathrm{h}$ light/12-h dark cycle.

All the rats were given humane treatment following the ethics specified in the "Guide for the Care and Use of Laboratory Animals" set by the Nationa 1 Academy of Science (NAS) and issued by the National Institute of Health. ${ }^{14}$ The experiment was performed in accordance with the United States NAS Guidelines and permission was obtained from the University Ethics Committee for Medical and Scientific Research (No. BFSC/18/127).

\section{Experimental Design}

We investigated TRECDS effect on the biomarkers of hepatic functions, antioxidant enzymes and oxidative stress indices following piroxicam exposure in rats. Rats were fasted overnight and water withdrawn for 3-4 $\mathrm{h}$ before the administration of the drug or the extract. Rats were weighed and randomly assigned to four groups of eight rats per group. The research design comprises concomitant oral administration of the rats with piroxicam (Ningbo 
Dahongying Pharmaceutical Industry Co. Ltd, Zhejiang, China) and TRECDS once daily for ten days according to the previous study. ${ }^{15}$

Group 1 were the normal control and were given 0.5 $\mathrm{mL}$ normal saline $(0.9 \% \mathrm{v} / \mathrm{v})$, group 2 received $20 \mathrm{mg} / \mathrm{kg}$ body weight piroxicam alone, group 3 were treated with $20 \mathrm{mg} / \mathrm{kg}$ body weight of piroxicam with concomitant administration of $200 \mathrm{mg} / \mathrm{kg}$ body weight of TRECDS, and group 4 were given $20 \mathrm{mg} / \mathrm{kg}$ body weight of piroxicam and concomitantly received of $400 \mathrm{mg} / \mathrm{kg}$ body weight of TRECDS. Twenty four hours after the last doses of the extract and/or piroxicam, about $5 \mathrm{~mL}$ of blood was collected by retro-orbital bleeding separately from each overnight-fasted rat and all the rats were sacrificed by cervical dislocation. The blood from each rat was collected into plain bottle, kept at room temperature $\left(28^{\circ} \mathrm{C}\right)$ and then centrifuged at $3000 \mathrm{~g}$ for ten minutes to get the serum. The serum was stored at $-20^{\circ} \mathrm{C}$ and used in evaluation of liver biochemical markers. Doses of the extract used were based on our previous studies.

\section{Liver Sample Preparation}

Portions of liver from each rat were collected into separate tube, rinsed with ice-cold saline, blotted and weighed then homogenized in cold $50 \mathrm{mM}$ Tris- $\mathrm{HCl}$ buffer $(\mathrm{pH} 7.4)$ containing $1.15 \%$ potassium chloride. The liver homogenate was afterward centrifuged at $12,000 \mathrm{x}$ g for $15 \mathrm{~min}$ at $4^{\circ} \mathrm{C}$ to obtain the post mitochondria fraction, and the supernatant was collected for antioxidant assays.

\section{Determination of Liver Function Markers}

The liver function markers were estimated using commercially available kits from Randox Laboratories Limited (Crumlin, UK). The assays comprise serum activities of alanine aminotransferase (ALT), aspartate aminotransferase (AST), alkaline phosphatase (ALP), gamma-glutamyl transferase (GGT), glucose-6-phosphate dehydrogenase $(\mathrm{G} 6 \mathrm{PDH})$ and concentrations of albumin (ALB), direct bilirubin, (dBIL) and total bilirubin (tBIL).

\section{Metabolic Parameters}

Levels of serum total cholesterol (CHOL), triglyceride (TRIGS), low-density lipoprotein (LDL), and high-density lipoprotein (HDL) were determined according to the manufacturer's instructions using commercially available diagnostic kits (Randox Laboratories Limited).

\section{Estimation of Liver Oxidative Stress and Antioxidant Markers}

Superoxide dismutase (SOD) activity was estimated as described ${ }^{16}$ whereas catalase (CAT) activity was determined using $\mathrm{H}_{2} \mathrm{O}_{2}$ as a substrate according to the method described by the previous study. ${ }^{17}$ Reduced glutathione (GSH) level was determined at $412 \mathrm{~nm}$ according to the method described by previous study. ${ }^{18}$ Lipid peroxidation (LPO) was quantified as malondialdehyde (MDA) according to method of previous study ${ }^{19}$ and the result was expressed as micromoles of MDA per milligram protein. Protein concentration was determined according to the method described by the previous study. ${ }^{20}$ All chemicals and reagents were purchased from Sigma Aldrich Chemical Co. (St. Louis, MO, USA) and British Drug House (Poole, Dorset, UK).

\section{Histopathological Examination}

Liver samples were fixed in $10 \%$ neutral buffered formaldehyde solution. After dehydration procedures, the samples were embedded in paraffin. Sections of 4-5 $\mu \mathrm{m}$ were cut by a microtome and stained with hematoxylin and eosin (H\&E). All slides were coded before examination with light microscope (Olympus $\mathrm{CH}$, Olympus, Tokyo, Japan) by pathologists who were blinded to normal control and treatment groups and photographed with a digital camera. ${ }^{21}$

\section{Statistical Analysis}

Statistical analysis was carried out using one-way analysis of variance (ANOVA) to compare the experimental groups followed by Duncan's test to identify significantly different groups (SPSS for Windows version 17, IBM Coorporation, Armonk, NY, USA). A $p<0.05$ was considered statistically significant.

\section{Results}

\section{Effect of PIRO and TRECDS Treatments on Rats'Body Weight and Relative Organ Weight}

The body weight and the relative liver weights of rats treated with piroxicam alone and piroxicam with TRECDS for 10 consecutive days are presented in Table 1. Administration of piroxicam alone decreased the final body weight and relative liver weights of the rats significantly $(p<0.05)$ when compared with the control (Group 1), but concomitant administration of piroxicam and TRECDS produced increased final body weights and relative organ weights of the rats significantly $(p<0.05)$ when compared with the 
Table 1. Body weight and relative organ weight (g/100g bw) of rats following exposure to piroxicam and TRECDS.

\begin{tabular}{lcccc}
\hline \multicolumn{1}{c}{ Variables } & Group 1 & Group 2 & Group 3 & Group 4 \\
\hline Initial body weight $(\mathrm{g})$ & $104.56 \pm 4.11$ & $108.35 \pm 3.20^{\mathrm{a}}$ & $120.13 \pm 3.02^{\mathrm{ab}}$ & $119.36 \pm 2.11^{\mathrm{b}}$ \\
Body weight gain (g) & $11.04 \pm 3.21$ & $-19.23 \pm 3.48^{\mathrm{a}}$ & $-5.74 \pm 1.72^{\mathrm{ab}}$ & $-2.10 \pm 2.51^{\mathrm{b}}$ \\
Relative liver weight $(\mathrm{g})$ & $5.28 \pm 0.45$ & $3.89 \pm 0.28^{\mathrm{a}}$ & $4.78 \pm 0.34^{\mathrm{ab}}$ & $4.98 \pm 0.19^{\mathrm{b}}$ \\
\hline
\end{tabular}

Each value represents mean \pm standard error of mean. ${ }^{\mathrm{a}} p<0.05$ was significant when compared to Group $1,{ }^{\mathrm{b}} p<0.05$ was significant when compared to Group 2.

piroxicam alone group (Group 2) and the increase was dose dependent. Additionally, Group 2 showed significant decreasing of body weight gain when compared with the control group. Co-administration of piroxicam and TRECDS significantly increased the body weight gain of the rats when compared with the rats in Group 2, but the increase was not significant when compared with the control $(\boldsymbol{p}<0.05)$.

A
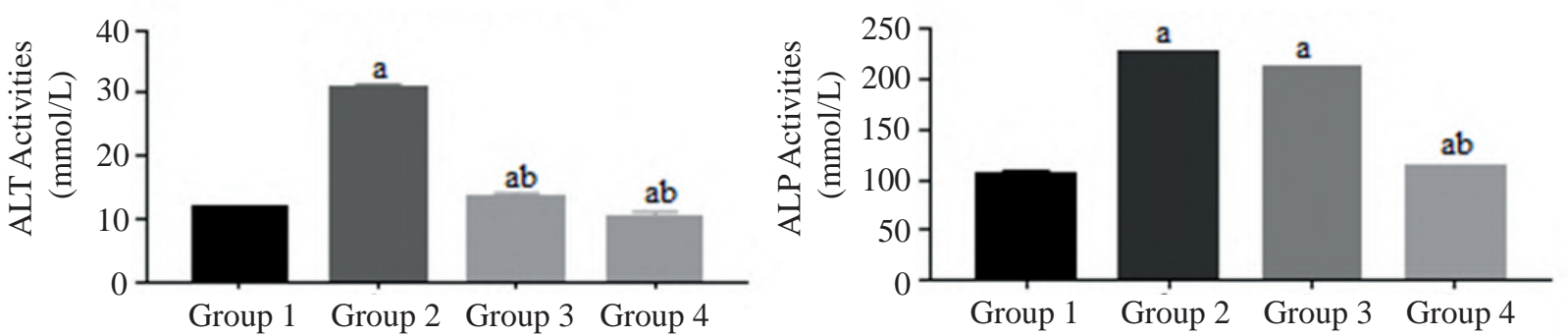

C

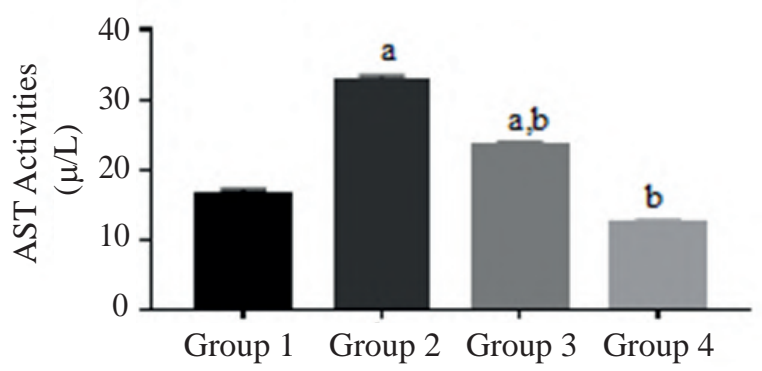

Effect of Piroxicam and TRECDS Treatments on Liver Function Markers

The results of hepatic function in rats treated with piroxicam and TRECDS for 10 days were presented in Figure 1 and 2. The activities of ALT, ALP, AST, GGT and G6PDH were significantly elevated following oral administration of piroxicam to rats $(p<0.05)$ when compared with the control (Group 1). Additionally, oral administration of piroxicam
B

D

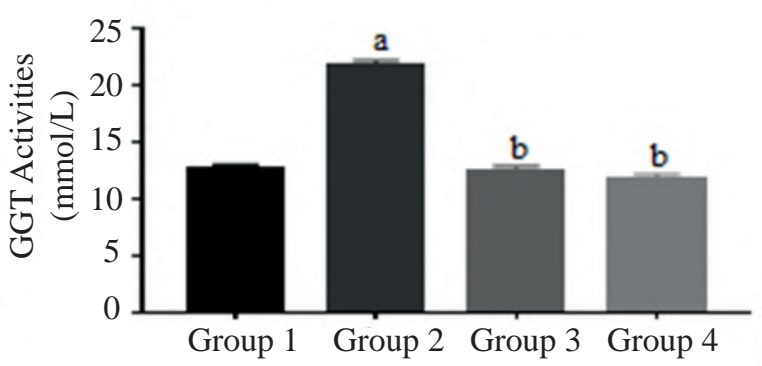

Figure 1. Effects of piroxicam and TRECDS on the activities of ALT (A), ALP (B), AST (C) and GGT (D) in rats' liver. Each bar represents mean \pm standard error of mean. ${ }^{\mathrm{a}} p<0.05$ was significant when compared to Group $1,{ }^{\mathrm{b}} p<0.05$ was significant when compared to Group 2. 
A

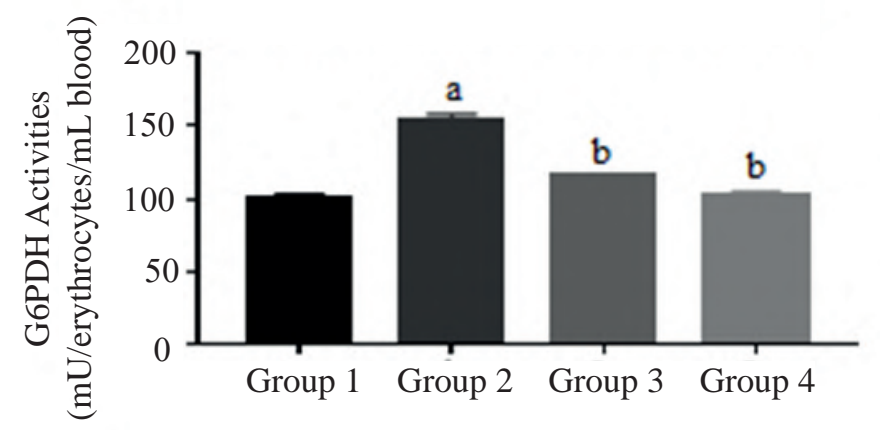

C

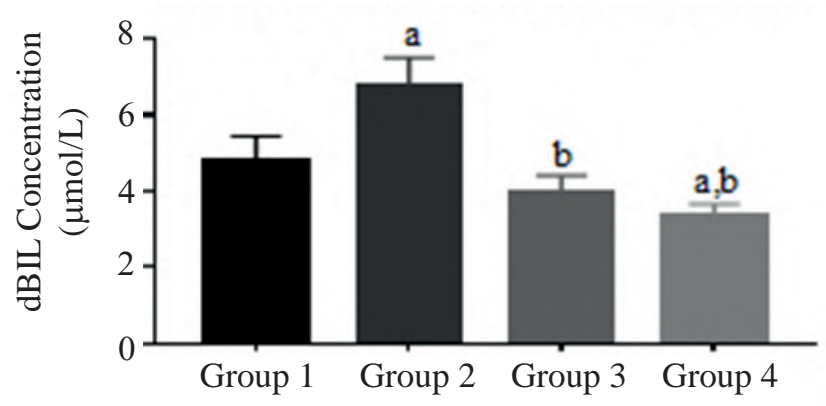

B

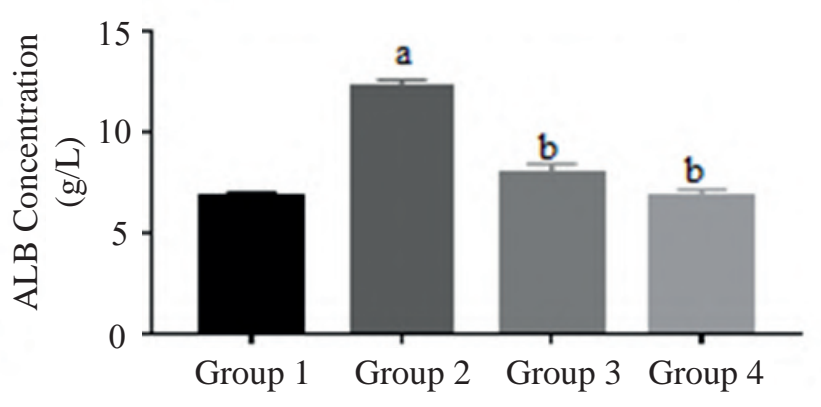

D

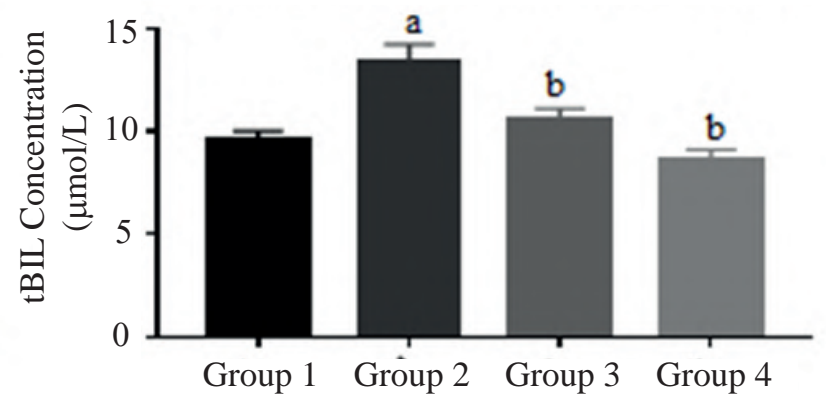

Figure 2. Effects of piroxicam and TRECDS on G6PDH activity (A), ALB concentration (B), dBIL concentration (C), and tBIL concentration (D) in rats liver. Each bar represents mean \pm standard error of mean. ${ }^{a} p<0.05$ was significant when compared to Group $1,{ }^{\mathrm{b}} p<0.05$ was significant when compared to Group 2.

increased the concentrations of ALB, dBIL and tBIL respectively when compared with the control group. But co-administration of piroxicam with TRECDS was able to decrease the activities of ALT, ALP, AST, GGT and G6PDH and the concentrations of ALB, dBIL and tBIL.

\section{Effect of Piroxicam and TRECDS Treatments on Lipid Profile}

Figure 3 showed that administration of piroxicam alone caused significant metabolic disorders in the rats. There was a significant $(p<0.05)$ decrease in HDL level in rats treated with piroxicam alone when compared with control. However, there was a marked increase in the levels of LDL, TRIGS, and CHOL in Group 2 when compared with the control $(p<0.05)$. But, following co-administration of 200 and $400 \mathrm{mg} / \mathrm{kg}$ TRECDS with piroxicam, there were significant dose-dependent increase in HDL. Furthermore, co-administration of 200 and $400 \mathrm{mg} / \mathrm{kg}$ TRECDS with piroxicam revealed a significant dose-dependent decrease in the levels of LDL, TRIGS, and CHOL when compared with the rats in Group 2.

\section{Effect of Piroxicam and TRECDS Treatments on Antioxidant Status}

Effects of oral administration of piroxicam and TRECDS on antioxidant defense system and biomarkers of oxidative stress were depicted in Figure 4. Administration of piroxicam alone caused significant $(p<0.05)$ decrease in antioxidant enzymes and GSH level, but produced significant $(p<0.05)$ elevations in the lipid peroxidation biomarkers in the liver when compared with the control.

Precisely, SOD and CAT activities in the liver decreased significantly following administration of piroxicam. Additionally, there were significant reduction in 
A

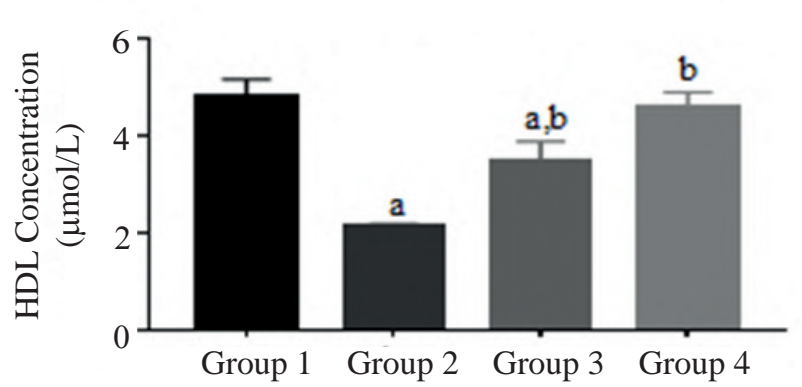

C

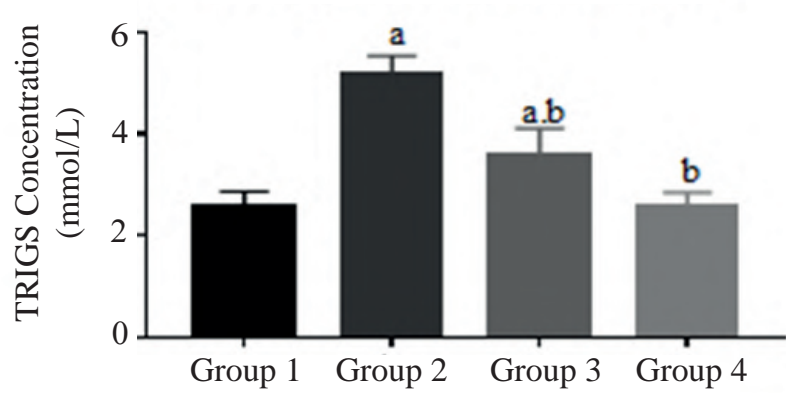

B

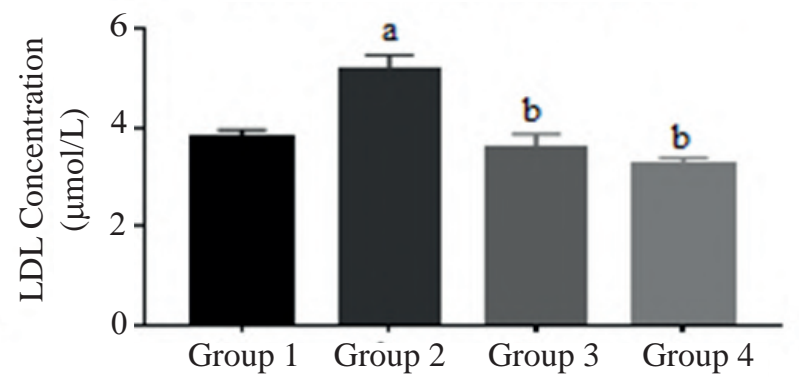

D

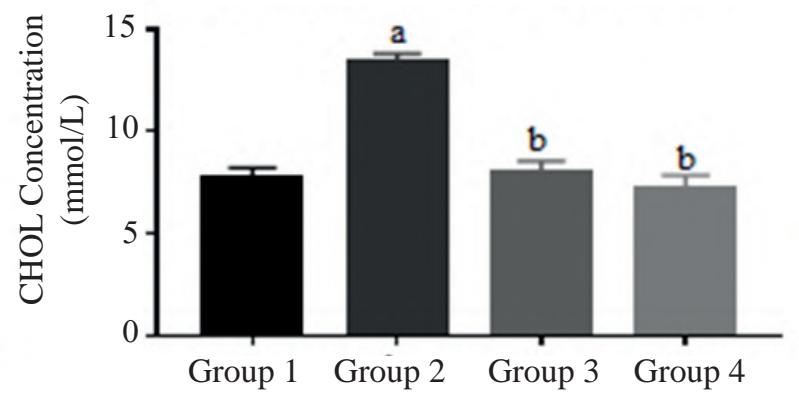

Figure 3. Effects of piroxicam and TRECDS on concentrations of HDL (A), LDL (B), TRIGS (C) and CHOL (D) in rats' liver. Each bar represents mean \pm standard error of mean. ${ }^{\mathrm{a}} p<0.05$ was significant when compared to Group $1,{ }^{\mathrm{b}} p<0.05$ was significant when compared to Group 2.

GSH levels in the liver of rats administered with PIRO alone when compared with the control $(p<0.05)$ with concomitant significant increase in MDA in the liver of rats administered with piroxicam alone when compared with the control. But co-administration of TRECDS with piroxicm significantly reversed the observation in a dose-dependent manner.

\section{Histological Observations of Liver of Rats Exposed to Piroxicam and TRECDS}

Figures 5 showed the representative photomicrographs of the liver from the experimental groups. The results of microscopic assessment of the liver are as follows. The liver of control rats appeared anatomically and functionally normal without any visible lesion (Figures 5A). In the liver, administration of piroxicam alone caused mild central venous congestion and cellular infiltration by neutrophils cells (Figure 5B) while co-administration of TRECDS at different doses improved the architectural appearance of the representative samples (Figures 5C and 5D).

\section{Discussion}

The relative organ weight is a vital index of swelling, atrophy or hypertrophy. A rise in this parameter presents an inflammatory condition while a reduction may be associated with cellular constriction. ${ }^{22}$ Hence, the decrease in the relative liver weight accompanying the decrease in the body weight gain may suggest cellular constriction. In the present study, administration of piroxicam produced a significant reduction in the body weights and the relative liver weights of the treated rats, thus demonstrating obvious organ toxicity in the rats.

The liver integrity of the normal control, piroxicam and TRECDS treated rats was determined by estimating serum biochemical markers together with microscopic examination of the liver. Aminotransferases serum activities possibly increase as a result of hepatocytes membrane destruction and leakage. The ratio of serum AST to ALT can be used to differentiate liver damage from other organ 
A

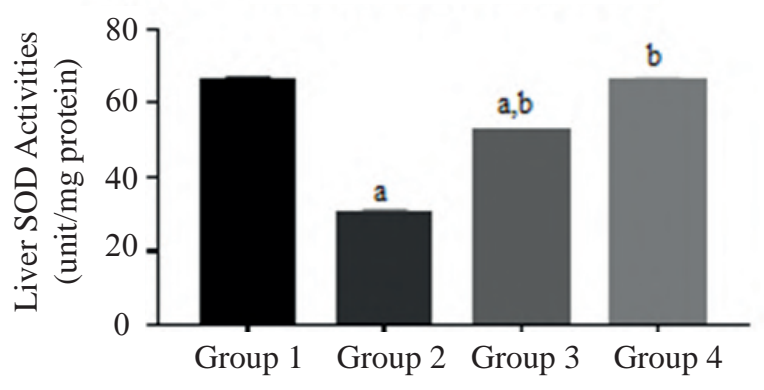

B

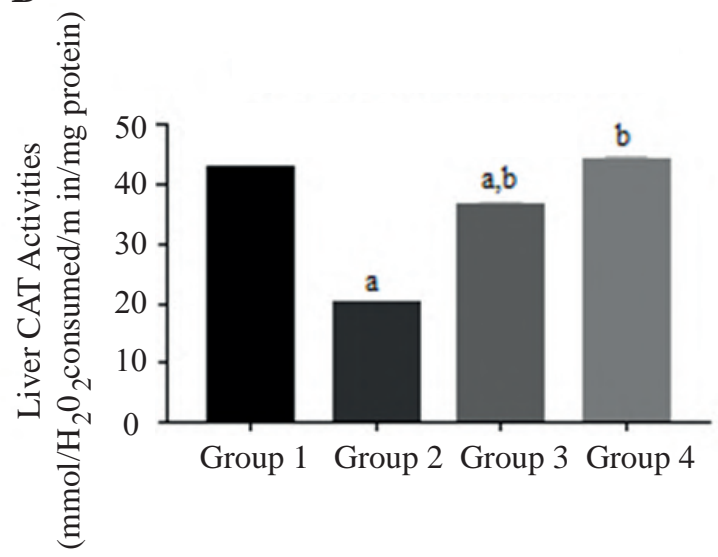

$\mathbf{C}$

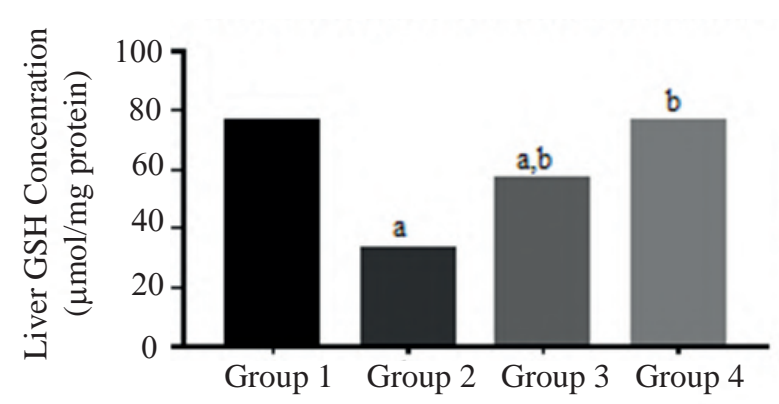

D

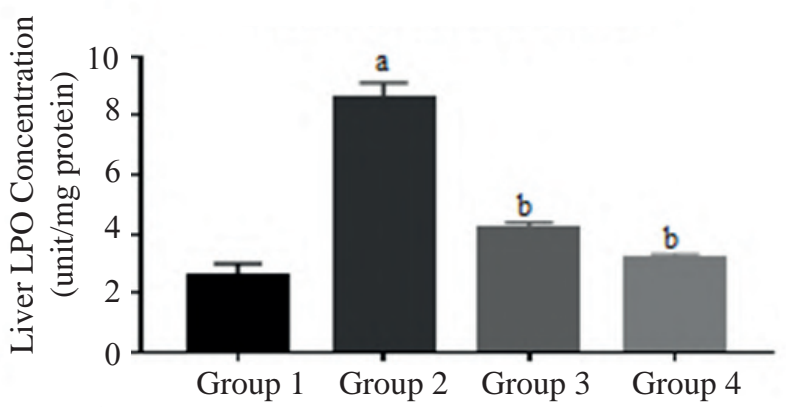

Figure 4. Activities and levels of SOD (A), CAT (B), GSH (C), and LPO (D) in the liver of rats following oral treatment with piroxicam and TRECDS for 10 consecutive days. Values are expressed as mean \pm SEM of eight rats. ${ }^{\mathrm{a}} p<0.05$ was significant when compared to Group $1,{ }^{\mathrm{b}} p<0.05$ was significant when compared to Group 2.

damage ${ }^{23}$ Serum elevations of ALT and AST observed in the piroxicam alone-treated rats indicate hepatic damage which may be associated with altered membrane permeability.

Alkaline phosphatase (ALP) is use to assess the integrity of the hepatobiliary system and flow of bile into the small intestine ${ }^{24}$, while gamma-glutamyl transferase is a specific biomarker of hepatobiliary injury. These two enzymes help to ascertain the occurrence of bone or liver injury and their raised level is indicative of liver or bile duct disease. In this study, rats that received piroxicam alone had elevated activities of ALP and GGT, this is in accordance with previous result ${ }^{25}$, but co-administration with different doses of TRECDS decreased the level of this enzyme.

Increase in bilirubin with little or no increase in ALT indicates cholestasis. This study revealed increased concentrations of total and direct bilirubin, an indication that piroxicam administration caused both hepatocellular and cholestasis injury to the liver. The results of this study conform to previous reports. ${ }^{26,27}$ Co-administration of piroxicam with 200 and $400 \mathrm{mg} / \mathrm{kg}$ body weight of TRECDS significantly decreased their levels.

The level of proteins in the blood will increase due to the inflow of protein from the damaged liver into the blood..$^{28}$ The results of this study showed that the concentrations of albumin and total protein increased in groups treated with piroxicam alone when compared with the normal control group. This is in accordance with previous report. ${ }^{29} \mathrm{But}$ co-administration with 200 and $400 \mathrm{mg} / \mathrm{kg}$ body weight of TREDS ameliorated these observations.

G6PDH antioxidant role has been reported and its activity can be altered as a result of cellular insult. In this study, the activity of G6PDH increased in PIRO alone treated rats. However, TREDS reversed this observation in a dose dependent manner. 

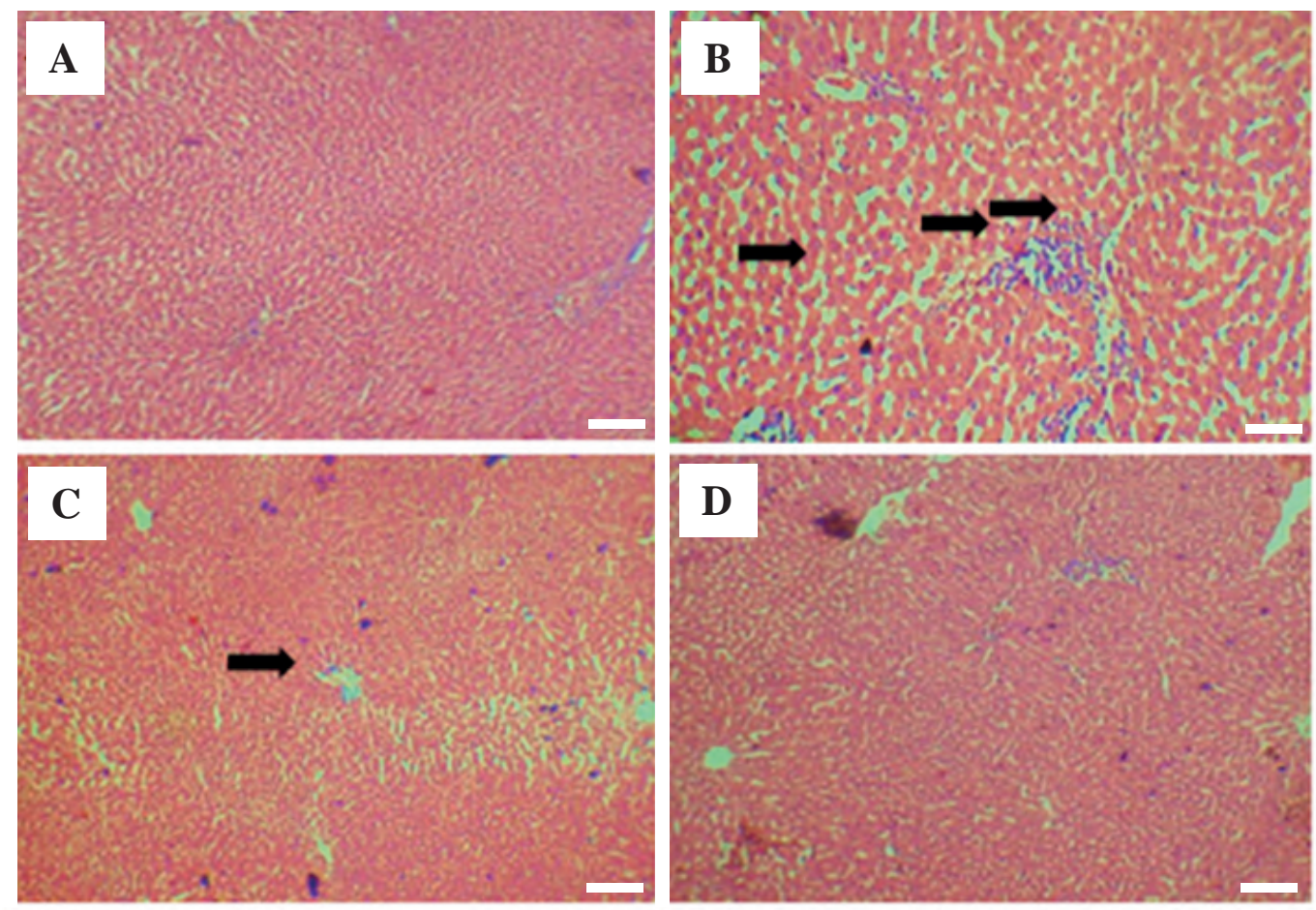

Figure 5. Photomicrographs of the liver. A: Group 1 showing normal architecture of liver; B: Liver of rats in Group 2 showing mild periportal penetration by inflammatory cells (black arrows); C: Group 3 with mild inflammation (black arrow); D: Rats' liver in Group 4 almost had complete restoration of the hepatocytes. H\&E 100x magnification, white bar:s100 $\mu \mathrm{m}$.

Variation in the concentrations of major lipids such as LDL, HDL, cholesterol, and triacylglycerol could offer useful information on the susceptibility to atherosclerosis. ${ }^{30}$ The elevations in atherogenic indices, serum levels of LDL, triacylglycerol, and cholesterol with a significant decline in the serum HDL level observed in the piroxicam alonetreated rats in the present study may indicate a possible disposition of the animals to dyslipidemia. Furthermore, TRECDS reversed these observations.

In an effort to explicate the mechanism of piroxicam action at subcellular echelons in the liver, we investigated its influence on the hepatic antioxidant status. The damaging effects of oxidative stress are normally offset by antioxidant defense apparatuses to protect the biological system against reactive oxygen species (ROS). Endogenous antioxidant enzymes are responsible for the detoxification of injurious oxygen radicals and their activities are used to assess oxidative stress in cells. The major cellular defense is normally obtained by a supportive relationship between metalloenzymes SOD and CAT. ${ }^{31}$ The activities of hepatic SOD and CAT were significantly diminished in rats treated with piroxicam alone in the present study. The decrease in the activities of these antioxidant enzymes may indicate inhibition of their defensive action against cellular oxidative damage in the rats. Scavenging of hydroxyl radical and singlet oxygen by glutathione is an important secondary line of defense against intracellular injurious effects of free radicals and peroxides generated by oxidative stress. The observed diminution in the hepatic GSH level in the present study may imply an increased demand or overutilization of GSH by the cell probably to fight ROS production in the piroxicam alone-treated rats. Unsaturated fatty acid residues of cellular constituents are commonly attacked by reactive oxygen species to generate peroxyl radicals and ultimately trans-4-hydroxy-2-nonenal and MDA. ${ }^{32}$ The present study showed an elevated level of LPO with concomitant depletion of the GSH level in piroxicam alone-treated rats; this result conformed with the earlier report. ${ }^{33}$ However, administration of TRECDS to rats significantly reverse these changes by suppressing LPO level and increasing GSH level. This may be due to the free radical scavenging properties of TRECDS and up regulation of the antioxidant enzymes activities.

The histopathological assessment of the liver of rats exposed to piroxicam alone showed mild central venous 
congestion and cellular infiltration by neutrophils. But, TRECDS restored the architecture of the liver in a dosedependent manner. These observations further support the biochemical results.

\section{Conclusion}

Overall, the results of this study showed that piroxicam induced liver damage and that TRECDS has the potentials to attenuate the hepatotoxicity caused by piroxicam probably due to its scavenging, ability upregulation of antioxidant mechanisms and hepatoprotective capacity.

\section{Acknowledgments}

The authors would like to appreciate the laboratory technologists of the Biochemistry Department of Bowen University, Iwo, Nigeria, for their kind assistances.

\section{References}

1. Di Salvo A, Giorgi M, Nannarone S, Lee HK, Coralini J, dellaRocca G. Postoperative pharmacokinetics of meloxicam in horses after surgery for colic syndrome. J Vet Pharmacol Ther. 2018; 41(3): 36973.

2. Benazir S, Ghosh D, Chattyopadhyay A. Protective effect of antioxidant rich aqueous curry leaf (Murraya koenigii) extract against gastro-toxic effects of piroxicam in male Wistar rats. Toxicol Rep. 2014; 1: 987-1003.

3. Abdeen A, Aboubakr M, Elgazzar D, AbdoM, Abdelkader A, Ibrahim S, Elkomy A. Rosuvastatin attenuates piroxicam-mediated gastric ulceration and hepato-renal toxicity in rats. Biomed Pharmacother. 2019: 110: 895-905.

4. Sriuttha P, Sirichanchuen B, Permsuwan U. Hepatotoxicity of nonsteroidal anti-inflammatory drugs: a systematic review of randomized controlled trials. Int J Hepatol. 2018: 2018: 5253623. doi: $10.1155 / 2018 / 5253623$.

5. Neha R, Munna S, Sanghamitra R. Piroxicam, a traditional nonsteroidal anti-inflammatory drug (NSAID) causes apoptosis by ROS mediated Akt activation. Pharmacologic Rep. 2015; 67(6): 1215-23.

6. Adedara IA, Teberen R, Ebokaiwe AP, Ehwerhemuepha T, Farombi EO. Induction of oxidative stress in liver and kidney of rats exposed to Nigerian bonny light crude oil. Environ Toxicol. 2012; 27(6): $372-9$.

7. Polidori MC, Stahl W, Eichler O, Niestroj I, Sies H. Profiles of antioxidants in human plasma. Fr Rad Biol Med. 2001; 30(5): 45662.

8. Adeyemi DO, Ukwenya VO, Obuotor EM, Adewole SO. Antihepatotoxic activities of Hibiscus sabdariffa L. in animal model of streptozotocin diabetes-induced liver damage. BMC Compl Altern Med 2014; 14: 277. doi: 10.1186/1472-6882-14-277.

9. Huang TW, Chang CL, Kao ES, Lin JH. Effect of Hibiscus sabdariffa extract on high fat diet-induced obesity and liver damage in hamsters. Food Nutr Res. 2015; 59: 29018. doi: 10.3402/fnr. v59.29018.
10. Mosango DM. Chasmanthera dependens hochst. In: Schmelzer GH, Gurib-Fakim A, editors. Plant Resources of Tropical Africa/ Ressources végétales de l'Afrique tropicale. Wageningen: PROTA; 2008. p.23-45.

11. Ogunlesi M, Okei W, Ademoye M. Medicinal plants used in treating eye infections in Nigeria. In: Odugbemi T, editor. A Textbook of Medicinal Plants from Nigeria. Lagos: University of Lagos Press; 2008. p.299-317.

12. Morebise O, Awe EO, Makinde JM, Olajide OA. Evaluation of the anti-inflammatory and analgesic properties of Chasmanthera dependens leaf methanol extract. Fitoterapia. 2001; 72(5): 497-502.

13. Fatokun OT, Wojuola TE, Esievo KB, Kunle OF. Medicinal plants used in the management of asthma: a review. EJPMR. 2016; 3(7): $82-92$.

14. US Department of Health and Human Services. Policy on Humane Care and Use of Laboratory Animals. Washington: US Department of Health and Human Services; 1996.

15. Aithal GP, Day CP. Nonsteroidal anti-inflammatory drug-induced hepatotoxicity. Clin Liver Dis. 2007; 11(3): 563-75.

16. Misra HP, Fridovich I. The role of superoxide anion in the autooxidation of epinephrine and a simple assay for superoxide dismutase. J Biol Chem. 1972; 247(10): 3170-5.

17. Sinha AK. Colorimetric Assay of Catalase. Anal Biochem. 1972; 47(2): 389-94.

18. Jollow DJ, Mitchell JR, Zampaglione N, Gillette JR. Bromobenzene induced liver necrosis: protective role of glutathione and evidence for 3,4-bromobenzene oxide as the hepatotoxic metabolite. Pharmacol. 1974; 11(3): 151-69.

19. Farombi EO, Tahnteng JG, Agboola AO, Nwankwo JO, Emerole GO Chemoprevention of 2-acetylaminofluorene-induced hepatotoxicity and lipid peroxidation in rats by kolaviron-a Garcinia kola seed extract. Food Chem Toxicol. 2000; 38(6): 535-41.

20. Lowry OH, Rosenbrough NJ, Farr AL, Randall RJ. Protein measurement with Folin phenol reagent. J Biol Chem. 1951; 193(1): 265-275.

21. Songur A, Akpolat N, Kus I, Ozen OA, Zararsiz I, Sarsilmaz M. The effects of the inhaled formaldehyde during the early postnatal period in the hippocampus of rats: a morphological and Immunohistochemical study. Neurosci Res Comm. 2003; 33(3): 168-178.

22. Moore KL, Dalley AF. Clinical Oriented Anatomy. 4th ed. Philadelphia: Lippincot Williams and Williams; 1999.

23. Ghouri N, Preiss D, Sattar N. Liver enzymes, non-alcoholic fatty liver disease, and incident cardiovascular disease: a narrative review and clinical perspective of prospective data. Hepatol. 2010; 52(3): 1156-61.

24. Singh A, Bhat TK, Sharma OP. Clinically biochemistry of hepatotoxicity. J Clinic Toxicol . 2011; S4: 001. doi:10.4172/21610495.

25. Sobeh M, Mahmoud MF, Abdelfattah MAO, El-Beshbishy HA, ElShazly AM, Wink M. Hepatoprotective and hypoglycemic effects of a tannin-rich extract from Ximenia americana var. caffra root. Int J Phythe Phytpharm. 2017; 33: 36-42.

26. Hussaini SH, Farrington EA. Idiosyncratic drug-induced liver injury: an update on the 2007 overview. Expert Opin Drug Saf. 2014; 13(1): 67-81.

27. Lina MAM, Amal KA. Biological effects of different doses of Piroxicam in albino male rats. Iraqi J Sci. 2017; 58(2c): 1009-19.

28. Franciscus A. An Overview of the Liver. Minnesota: Health Care Savings Plan (HCSP); 2015. 
29. Swagata P, Bhattacharjee A, Mukherjee S, Bhattacharya K, Khowala S. Antioxidant and hepatoprotective activity of ethanolic extract of Alocasia indica Tuber. AJPCT. 2014; 2(2): 191-208.

30. Yakubu MT, Akanji MA, Oladiji AT. Alterations in serum lipid profile of male rats by oral administration of aqueous extract of Fadogia agrestis stem. Res J Med Plant. 2008; 2(2): 66-73.

31. Adedara IA, Farombi EO. Induction of oxidative damage in the testes and spermatozoa and hematotoxicity in rats exposed to multiple doses of ethylene glycol monoethyl ether. Hum Exper Toxicol. 2010; 29(10): 801-12.

32. Avery SV. Molecular targets of oxidative stress. Biochem J. 2011; 434(2): 201-10.

33. Sangeetha LAR, Samixaben Patel D, Chetan Pandanaboina S. Hepato-protective effects of blue-green alga spirulina platensis on diclofenac-induced liver injury in rats. Mal J Nutr. 2016; 22(2): 289-99. 